\title{
Acute Brucellosis with Myelodysplastic Syndrome Presenting as Pancytopenia and Fever of Unknown Origin
}

\author{
Jun-Jie Li ${ }^{\mathrm{a}}$ Zi-Ke Sheng ${ }^{\mathrm{a}} \mathrm{b}$ Sheng $\mathrm{Tu}^{\mathrm{c}}$ Sheng $\mathrm{Bi}^{\mathrm{a}}$ Xiao-Min Shen ${ }^{\mathrm{a}}$ \\ Ji-Fang Sheng ${ }^{a}$ \\ a Department of Infectious Diseases, State Key Laboratory for Diagnosis and Treatment of Infectious Diseases, \\ First Affiliated Hospital of Medical College, Zhejiang University, ${ }^{b}$ Children's Hospital, Zhejiang University School \\ of Medical College, and ${ }^{C}$ First Affiliated Hospital of Zhejiang Chinese Medical University, Hangzhou, China
}

\section{Key Words}

Infection - Leukopenia · Thrombocytopenia - Clonal hemopoietic disorder

\begin{abstract}
Objective: To report a rare case of brucellosis with myelodysplastic syndrome (MDS). Clinical Presentation and Intervention: A 70-year-old woman presented with pancytopenia and fever of unknown origin (FUO). The initial diagnosis was brucellosis; the woman was treated with doxycycline and rifampin against Brucella melitensis but was later diagnosed as suffering from MDS. She was immediately transferred to the Department of Hematology for further evaluation. Conclusion: This study highlights the rarity of brucellosis with MDS, and we recommend that brucellosis with MDS be considered in patients presenting with pancytopenia and FUO.

Copyright $\odot 2011$ S. Karger AG, Basel
\end{abstract}

\section{Introduction}

Myelodysplastic syndrome (MDS) and brucellosis are both causes for pancytopenia and fever of unknown origin (FUO) [1, 2]. The FUO was originally defined in 1961 by Petersdorf and Beeson [3] as recurrent fever of $>38.3^{\circ} \mathrm{C}$ lasting 3 weeks or more, and unexplained after detailed clinical investigations for at least 1 week. The causes for FUO are various and mainly classified as infectious, malignant, noninfectious inflammatory disease, and unknown cause $[1,4]$. On the other hand, pancytopenia indicates itself through the dramatic decrease in the amount of white blood cells, hemoglobin and platelets in the same patient. It is generally caused by bone marrow diseases, hypersplenism, chemotherapeutic agents as well as infection. To our knowledge, brucellosis associated with MDS is extremely rare. We herein report an unusual case of it.

\section{Case Report}

A 70 -year-old woman who had spent 10 days in the local community hospital was referred to our hospital with a 20-day duration of fever $\left(>39^{\circ} \mathrm{C}\right)$, night sweats, chilling, weakness, weight loss, paleness and pancytopenia, without jaundice and hepatosplenomegaly. Otherwise, she was healthy and without a history

\section{KARGER}

Fax +41613061234 E-Mail karger@karger.ch www.karger.com
Ji-Fang Sheng

Department of Infectious Diseases, State Key Laboratory for Diagnosis and Treatment of Infectious Diseases, First Affiliated Hospital, School of Medicine Zhejiang University, Qingchun Road 79, Hangzhou 310003 (China)

Tel. +865718723 6759, E-Mail jifangsheng9200@163.com 
of taking toxic drugs or receiving immunosuppressive treatment. Detailed physical examination and extensive investigations for FUO were performed. Physical examination revealed that she was quite exhausted, with pallor of the skin and a high-grade fever $\left(40.5^{\circ} \mathrm{C}\right)$. Her blood pressure was $112 / 64 \mathrm{~mm} \mathrm{Hg}$ and the pulse rate was 65 beats/min. The laboratory examination results were as follows: complete blood count with white blood cells $2.0 \times 10^{9} / 1$ (50.5\% lymphocytes, $15.8 \%$ monocytes, $33.7 \%$ neutrophils), hemoglobin $70 \mathrm{~g} / 1$, platelets $34 \times 10^{9} / 1$; C-reactive protein $94.20 \mathrm{mg} / \mathrm{l}$; erythrocyte sedimentation rate $101 \mathrm{~mm} / \mathrm{h}$; total protein $57.1 \mathrm{~g} / \mathrm{l}$; albumin $29.7 \mathrm{~g} / \mathrm{l}$; international normalized ratio 1.16 ; fibrinogen $5.1 \mathrm{~g} / \mathrm{l}$; partial thromboplastin time $44.2 \mathrm{~s}$; prothrombin time $13.3 \mathrm{~s}$. The liver and the renal function tests were normal. Antinuclear antibodies were within the normal range. Serological tests were negative for hepatitis B and C virus, Epstein-Barr virus, Coxsackie, echovirus, HIV, cytomegalovirus, Mycoplasma and Salmonella. In the local community hospital, the examination of pulmonary computed tomography $(\mathrm{CT})$ revealed bronchitis with infection whereas blood cultures were negative in both the local and our hospital. In order to further investigate the cause of FUO and to exclude a neoplasm, fluorine-18 fluorodeoxyglucose positron emission tomography/CT was performed, the images of which suggested hypermetobolism in the spine, sternum and pelvis. Bone marrow examination revealed slight myelofibrosis with hypercellularity, and MDS was not excluded due to a slight increase in blasts. Although the antibiotic agents and transfusion were performed, the fever and pancytopenia were still out of control, with deteriorating condition.

On day 15 after admission, the rose bengal plate agglutination test was positive, and the standard tube agglutination test for $\mathrm{Bru}$ cella was positive at a titer of $1 / 160$. The patient lived in a rural area and had a history of direct contact with her pet dog, which was a potential source of infection. Thus, brucellosis was diagnosed and then the patient was treated with oral rifampin $300 \mathrm{mg}$ twice a day plus oral doxycycline $100 \mathrm{mg}$ twice a day. Three weeks later, there was a slight clinical improvement. Due to the progressive pancytopenia (white blood cells $2.0 \times 10^{9} / 1$, hemoglobin $53 \mathrm{~g} / \mathrm{l}$, platelets $8 \times 10^{9} / \mathrm{l}$ ) and the persistence of high-grade fever, weight loss and paleness, a hematological malignancy was strongly suspected. Therefore, another bone marrow aspiration and biopsy were performed. A moderate myelofibrosis bone marrow coexisting with hypercellularity was noted, and an increase in the proportion of blasts (8.5\%) with morphological abnormalities which suggested MDS with a subtype of refractory anemia with excess of blasts I (RAEB-I), according to the World Health Organization classification for MDS, was found [5]. Thus, MDS RAEB-I was diagnosed. Then she was transferred to a local hospital for further evaluation and management, and unfortunately she died due to persistent pancytopenia and high-grade fever.

\section{Discussion}

In our report, repeated blood and bone marrow cultures were negative, which did not support an infection. However, brucellosis was established when the rose bengal plate agglutination and standard tube agglutination tests were positive, which suggested the diagnosis of bru- cellosis. On the other hand, the progressive hematological abnormality and the deteriorating condition of the patient indicated a hematological disorder, especially a hematological neoplasm. MDS was confirmed by the bone marrow examination. Although the initial diagnostic workup for FUO and pancytopenia was negative, brucellosis with MDS should not be excluded from the differential diagnosis list.

Brucellosis is a worldwide zoonosis, and the major sources of infection are contagious animals and the contaminated products made from them. Moreover, brucellosis is a systemic disease in which several different organ systems may be involved. In contrast, MDS is a clonal disorder of bone marrow stem cells with ineffective hematopoiesis, which may progress and transform to acute myeloid leukemia. Primary MDS usually has no clear-cut cause, while secondary MDS commonly occurs after exposure to toxic agents, radiation or both [6].

MDS undergoes a variety of changes in the hematological parameters with brucellosis, such as anemia, leukopenia, pancytopenia and myelofibrosis. Although most MDS patients are prone to develop progressive pancytopenia, it is rarely observed in brucellosis $[7,8]$. The mechanism of pancytopenia in brucellosis has not been clearly established. A variety of possible causes have been published, including hemophagocytosis, hypersplenism, bone marrow granuloma lesion formation, immune destruction, bone marrow hypoplasia and myelofibrosis [8].

The present report describes an exceptional case of coexistence of brucellosis and MDS with a subtype of RAEB-I. Brucellosis in association with hematological malignancies, such as acute myeloid leukemia and acute lymphoblastic leukemia, has been reported [9]. To our knowledge, brucellosis associated with MDS is rarely reported. The relationship between brucellosis and hematological malignancies remains unknown. A hematological neoplasm may be part of the blood picture changes seen in brucellosis.

\section{Conclusions}

The present study highlights the rarity of brucellosis with MDS. Because clinical manifestations of brucellosis are not specific, practitioners in nonendemic areas may not be familiar. In addition, brucellosis in association with MDS is extremely rare. These may result in diagnostic delay. Therefore, we recommend that brucellosis with MDS be considered in patients with pancytopenia and FUO, especially in endemic areas. 


\section{Acknowledgements}

The authors thank Dr. Yi-Da Yang, Wen-Bin Qian and XiangMin Tong for comments on the manuscript. This study was sponsored by the National Basic Research Programs (973) of China (No. 2007CB513004) and the Major National S\&T Projects for infectious diseases (11th Five Year; 2008ZX10002-007).

\section{Disclosure Statement}

The authors declare that they have no competing interests.

\section{References}

1 Colpan A, Onguru P, Erbay A, Akinci E, Cevik MA, Eren SS, Bodur H: Fever of unknown origin: analysis of 71 consecutive cases. Am J Med Sci 2007;334:92-96.

2 Aysha MH, Shayib MA: Pancytopenia and other haematological findings in brucellosis. Scand J Haematol 1986;36:335-338.

3 Petersdorf RG, Beeson PB: Fever of unexplained origin: report on 100 cases. Medicine (Baltimore) 1961;40:1-30.
4 Kucukardali Y, Oncul O, Cavuslu S, Danaci M, Calangu S, Erdem H, Topcu AW, Adibelli Z, Akova M, Karaali EA, Ozel AM, Bolaman Z, Caka B, Cetin B, Coban E, Karabay O, Karakoc C, Karan MA, Korkmaz S, Sahin GO, Pahsa A, Sirmatel F, Solmazgul E, Ozmen N, Tokatli I, Uzun C, Yakupoglu G, Besirbellioglu BA, Gul HC: The spectrum of diseases causing fever of unknown origin in Turkey: a multicenter study. Int J Infect Dis 2008;12:71-79.

5 Harris NL, Jaffe ES, Diebold J, Flandrin G, Muller-Hermelink HK, Vardiman J, Lister TA, Bloomfield CD: World Health Organization classification of neoplastic diseases of the hematopoietic and lymphoid tissues: report of the clinical advisory committee meeting - Airlie House, Virginia, November 1997. J Clin Oncol 1999;17:3835-3849.

6 Cazzola M, Malcovati L: Myelodysplastic syndromes - coping with ineffective hematopoiesis. N Engl J Med 2005;352:536-538.
7 Akdeniz H, Irmak H, Seckinli T, Buzgan T, Demiroz AP: Hematological manifestations in brucellosis cases in Turkey. Acta Med Okayama 1998;52:63-65.

-8 Erkurt MA, Sari I, Gul HC, Coskun O, Eyigun CP, Beyan C: The first documented case of brucellosis manifested with pancytopenia and capillary leak syndrome. Intern Med 2008:47:863-865.

9 Sari I, Altuntas F, Hacioglu S, Kocyigit I, Sevinc A, Sacar S, Deniz K, Alp E, Eser B, Yildiz O, Kaynar L, Unal A, Cetin M: A multicenter retrospective study defining the clinical and hematological manifestations of brucellosis and pancytopenia in a large series: hematological malignancies, the unusual cause of pancytopenia in patients with brucellosis. Am J Hematol 2008;83:334-339. 